\title{
Microbial Contamination in Hospital Environment Has the Potential to Colonize Preterm Newborns' Nasal Cavities
}

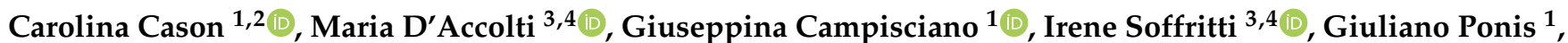 \\ Sante Mazzacane ${ }^{4}$, Adele Maggiore ${ }^{5}$, Francesco Maria Risso ${ }^{6}$, Manola Comar ${ }^{1,2, *}$ and Elisabetta Caselli ${ }^{3,4}$ (D)
}

1 Department of Advanced Translational Microbiology, Institute for Maternal and Child Health—IRCCS “Burlo Garofolo", 34137 Trieste, Italy; carolina.cason@burlo.trieste.it (C.C.); giusi.campisciano@burlo.trieste.it (G.C.); giuliano.ponis@gmail.com (G.P.)

2 Department of Medical Sciences, University of Trieste, 34137 Trieste, Italy

3 Department of Chemical and Pharmaceutical Sciences, Section of Microbiology and LTTA, University of Ferrara, 44121 Ferrara, Italy; maria.daccolti@unife.it (M.D.); irene.soffritti@unife.it (I.S.); elisabetta.caselli@unife.it (E.C.)

4 CIAS Research Centre, University of Ferrara, 44122 Ferrara, Italy; sante.mazzacane@unife.it

5 Institute for Maternal and Child Health-IRCCS "Burlo Garofolo", 34137 Trieste, Italy; adele.maggiore@asuits.sanita.fvg.it

6 Department of Neonatology, Institute for Maternal and Child Health-IRCCS "Burlo Garofolo", 34137 Trieste, Italy; francescomaria.risso@burlo.trieste.it

* Correspondence: manola.comar@burlo.trieste.it

\section{check for} updates

Citation: Cason, C.; D'Accolti, M.; Campisciano, G.; Soffritti, I.; Ponis, G.; Mazzacane, S.; Maggiore, A.; Risso, F.M.; Comar, M.; Caselli, E. Microbial Contamination in Hospital Environment Has the Potential to Colonize Preterm Newborns' Nasal Cavities. Pathogens 2021, 10, 615. https://doi.org/10.3390/ pathogens 10050615

Academic Editor: Carmelo Biondo

Received: 12 March 2021

Accepted: 14 May 2021

Published: 17 May 2021

Publisher's Note: MDPI stays neutral with regard to jurisdictional claims in published maps and institutional affiliations.

Copyright: (c) 2021 by the authors. Licensee MDPI, Basel, Switzerland. This article is an open access article distributed under the terms and conditions of the Creative Commons Attribution (CC BY) license (https:// creativecommons.org/licenses/by/ $4.0 /)$.

\begin{abstract}
Infants born before 28 weeks are at risk of contracting healthcare-associated infections (HAIs), which could be caused by pathogens residing on contaminated hospital surfaces. In this longitudinal study, we characterized by NGS the bacterial composition of nasal swabs of preterm newborns, at the time of birth and after admission to the Neonatal Intensive Care Unit (NICU), comparing it with that of the environmental wards at the time of delivery and during the hospitalization. We characterized the resistome on the samples too. The results showed that environmental microorganisms responsible for HAIs, in particular Staphylococcus spp., Streptococcus spp., Escherichia-Shigella spp., and K. pneumoniae, were detected in higher percentages in the noses of the babies after 13 days of hospitalization, in terms of the number of colonized patients, microorganism amount, and relative abundance. The analysis of nasal bacteria resistome evidenced the absence of resistance genes at the time of birth, some of which appeared and increased after the admission in the NICU. These data suggest that hospital surface microbiota might be transported to respiratory mucosae or other profound tissues. Our study highlights the importance of a screening that allows characterizing the microbial profile of the environment to assess the risk of colonization of the newborn.
\end{abstract}

Keywords: healthcare associated infections; preterm newborns; antimicrobial resistance genes; microbiome; environmental microbial contamination

\section{Introduction}

Extremely preterm infants, born before 28 weeks, receiving care in a Neonatal Intensive Care Unit (NICU) are at high risk for contracting healthcare-associated infections (HAIs) [1,2]. HAIs are significant causes of morbidity and mortality in NICUs [3], with a prevalence that goes from $6 \%$ to $50 \%$ and mortality between $20 \%$ and $80 \%$, depending on the risk factors $[4,5]$.

The immaturity of newborns (so defined in the first 28 days of life) is linked to more immature immune responses, explaining their vulnerability to pathogens [6,7], which contributes to the occurrence of healthcare-associated infections. Invasive diagnostic and therapeutic procedures represent additional risk factors for pathogenetic NICU patients $[6,8]$. 
Neonatal infections are classified into early onset infections (occurring in the first $72 \mathrm{~h}$ of life) contracted at the time of delivery and late-onset infections, which occur after $72 \mathrm{~h}$ from birth, related to acquisition at home, or in hospital settings [9]. Among infants born preterm, early onset sepsis often represents a fatal illness, particularly among newborn infants of the lowest gestational age. Bacterial bloodstream infection is one of the most common events in hospitalized newborns [10], mainly caused by coagulase negative staphylococci [11].

Neonatal sepsis shares symptoms with other health conditions and is difficult to diagnose in the laboratory, which leads to a tendency to overdiagnose and treat this pathology. The extremely preterm infants with very low birth weight (VLBW) are treated with antibiotics, often for prolonged periods, in the absence of a confirmed infection [12-15]. Antibiotic exposures after birth are associated with multiple subsequent several negative outcomes, such as the development of asthma [16], allergies, prolonged hospitalization, multidrug-resistant bacterial infections [17], and even obesity later in life [18], making the risk/benefit balance of these approaches uncertain [16-23].

Nevertheless, the association between inadequate use of antibiotics and an increase of neonatal resistant bacterial HAIs in neonatal units has been reported [24].

For example, the main microorganisms responsible for hospital infections include Methicillin-resistant Staphylococcus aureus (MRSA), Carbapenem-resistant Enterobacteriaceae, Vancomycin-resistant Enterococci (VRE), and multidrug-resistant (MDR) Clostridium difficile, Acinetobacter spp., and Pseudomonas aeruginosa [25].

Additionally, fungi are involved, in particular invasive fungal infections due to Candida spp. are the third most common LOS in VLBW infants [26] with a higher incidence in NICU wards than in other paediatric or adult populations [27].

Among the main diseases associated with infections contracted in neonatal hospital settings, late onset sepsis (LOS) is considered the main cause of morbidity and mortality among preterm infants $[28,29]$, with serious sequelae in surviving infants including necrotizing enterocolitis, bronchopulmonary dysplasia, and neurodevelopmental impairment [30]. A large proportion of all LOS is represented by central line-associated bloodstream infections (CLABSIs) [31]. LOS has been shown to be mainly caused by coagulase-negative staphylococci (CoNS) (39\%), followed by Escherichia coli (9\%) [32]. Other conditions frequently linked to HAIs in newborns are ventilator-associated pneumonia, mainly caused by Gram-negative bacteria [33] and ventricular shunt infections, mainly caused by Grampositive organisms [34]. The risk of those pathologies increases with the low weight of the newborn, the gestational age, and the prolonging of the medical practice $[26,35,36]$.

In recent years, there has been a growing interest in the role of the contaminated hospital environment in the transmission of HAIs [37]. Contaminated surfaces act as a reservoir for many pathogens, including those from the patients themselves [38], and can, therefore, be a substantial source for transmission of hospital infections [39,40]. Microorganisms can maintain their infectivity on dry inanimate surfaces even for weeks, and some spores can survive for months [41].

NICU surfaces harbour a large number of bacterial and fungal taxa, including members associated with HAIs in neonates. Recent studies have investigated the hypothesis that colonies of pathogenic agents on the surfaces of NICUs may increase the risk of infection for premature infants, without showing a species-specific causal association between environmental contamination and neonatal infection $[42,43]$.

Recently, the approach based on next-generation sequencing (NGS) has emerged as a comprehensive and fast tool for disease surveillance and evolutionary analysis of infectious diseases $[44,45]$. By using NGS in this observational study we aimed to explore how the environmental microbiome can colonize the upper respiratory tract of preterm infants and which bacteria are most impactful in the clinical surveillance procedures usually adopted by the hospital. A multiple time-point analysis of nasal swabs of preterm newborns and environmental surface samples was performed simultaneously, collecting one set of samples at birth, and two set of samples during the period of hospitalization in the NICU. 


\section{Results}

\subsection{The Microbial Profile of Newborns Nasal Swabs}

A longitudinal study was carried out analysing the bacterial composition of nasal swabs, of low-weight preterm newborns at birth (group N0) and after admission to the NICU (group N9 after 9 days, and group N13 after 13 days of permanence in the ward) comparing it with that of the environmental surfaces of the wards at the time of delivery and during the period of hospitalization.

\subsection{NGS Analysis}

The analysis of nasal swabs by NGS led to the identification of bacterial genera Corynebacterium spp., Staphylococcus spp., Streptococcus spp., Escherichia-Shigella spp., Acinetobacter spp., Pseudomonas spp., Klebsiella spp., Enterobacter spp., Lactobacillus spp., Cutibacterium spp., Stenotrophomonas spp., Haemophilus spp., Gemella spp., and Rothia spp. as shown in Figure 1A. This figure reports the percentage of patients colonized by bacteria for each of the examined groups (N0, N9, and N13). Corynebacterium spp., Staphylococcus spp., Streptococcus spp., Escherichia-Shigella spp., Klebsiella spp., and Enterobacter spp. showed higher percentages of colonized patients in the N13 group, including newborns after 13 days of permanence in NICU. On the other hand, Cutibacterium spp. and Pseudomonas spp. had higher percentages in infants at the time of birth (N0).

A $\square \mathrm{N} 0 \mathrm{N9}=\mathrm{N} 13$

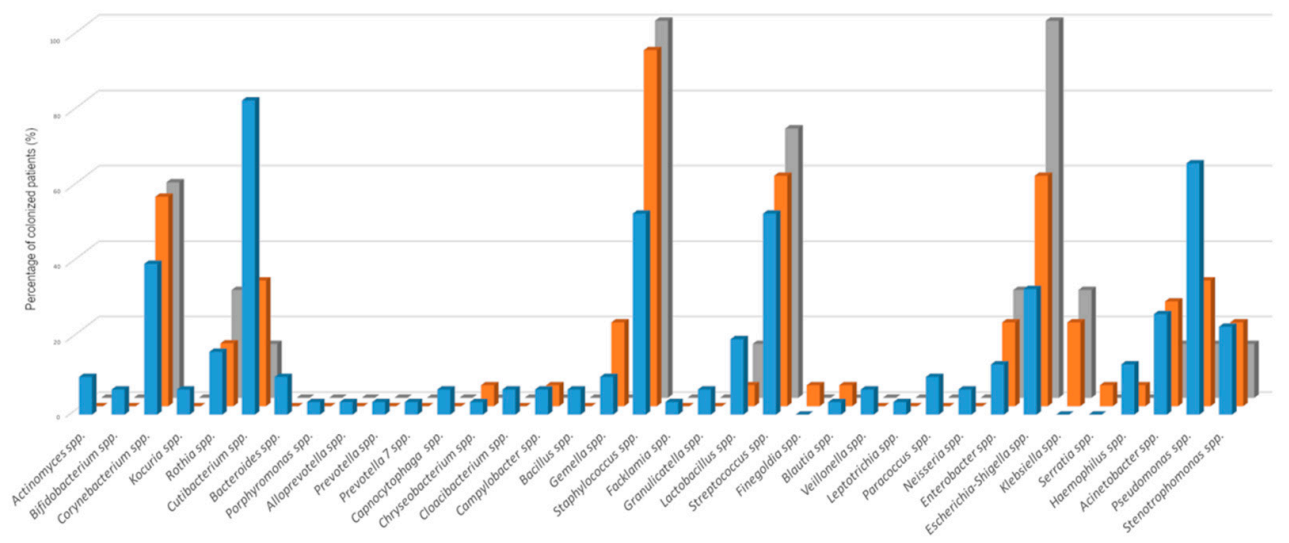

B

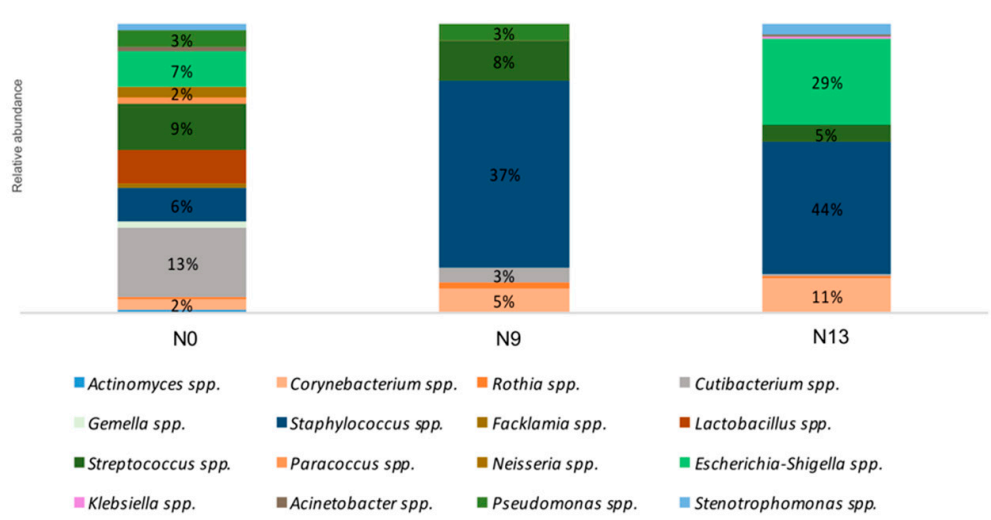

Figure 1. The most abundant bacterial communities of nasal swabs from newborns at time of birth and after two follow-ups. Results were obtained by NGS. (A) Percentage of colonized patients for each genus; (B) mean of bacterial relative abundances for each group. N0: samples collected at time of birth. N9: samples collected after 9 days of permanence in NICU. N13: sample collected after 13 days of permanence in NICU. 
As for the average of the relative abundances for each genus within the three groups Corynebacterium spp., Staphylococcus spp., and Escherichia-Shigella spp. demonstrated an increase of relative abundance from the group N0 to the group N13: Corynebacterium spp. (N0: 2\%; N9: 5\%; N13: 11\%), Staphylococcus spp. (N0: 6\%; N9: 37\%; N13: 44\%), and Escherichia-Shigella spp. (N0: 7\%; N9: 0\%; N13: 29\%) (Figure 1B). The observed differences were statistically assessed by Kruskal-Wallis test, showing significance concerning Staphylococcus spp. (FDR $p=0.047$ ) and Escherichia-Shigella spp. (FDR $p=0.047$ ). For these two bacterial genera there was an increasing trend both in the number of colonized subjects and in the relative abundance value (Figure 1).

\subsection{Bacterial Composition of Vaginal Swabs in Pregnant Women}

To evaluate the contribution of vaginal bacteria in the colonization of the nasal microbiome of newborns, we analysed 20 vaginal swabs from women before giving birth in the delivery room (DR) (Figure 2). The detected bacteria were in line with previous data (Freitas et al., 2018; Fettweis et al., 2019). Lactobacillus spp., representing the predominant vaginal genus, was found with a relative abundance of $6 \%$ in $20 \%$ of newborns (N0), higher than the other groups considered. Prevotella spp. was detected only in 3\% of N0 group, and Streptococcus spp. was detected with higher relative abundance in the N0 group ( $9 \%$ in the $53 \%$ of the babies of the group) than N9 and N13.

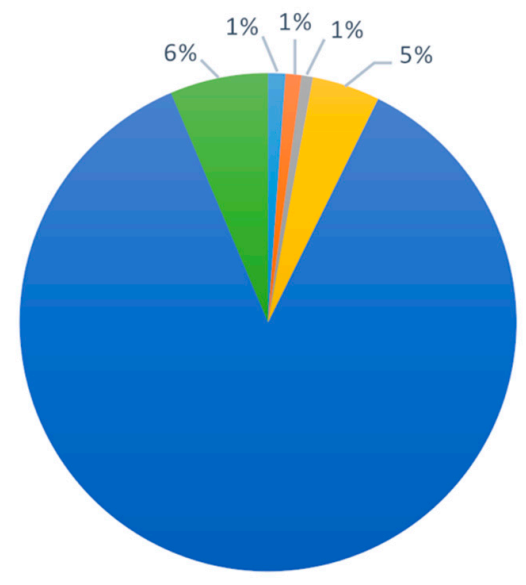

$86 \%$

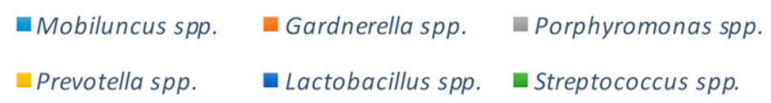

Figure 2. Predominant bacterial communities of vaginal swabs from pregnant women. Results were obtained by NGS. Data are represented as mean relative abundances.

\subsection{Impact of the Environmental Bacterial Microbiome on Nasal Colonization of Newborns}

We explored the influence of the environmental microbiome on newborns' nasal colonization considering the environmental microbiome of the DR (N0 vs. DR) and of NICU, collected after baby's permanence in this structure (N9 vs. NICU and N13 vs. NICU). The bacterial diversity was compared using the unweighted and weighted UniFrac distance matrices, the results are visualized by a Principal Coordinates Analysis (PCoA), both with weighted and unweighted UniFrac. A one-way Analysis of Similarity (ANOSIM) statistical test was applied to the UniFrac distance matrices to test the significant differences according to the clinical grouping. For the comparison between the group N0 and DR (Figure 3A), ANOSIM attributed a significant difference to the grouping for the unweighted UniFrac ( $p=0.001, \mathrm{R}=0.9)$, but not for the weighted UniFrac $(p=0.8, \mathrm{R}=-0.12)$. For the N9 and NICU groups (Figure 3B), ANOSIM attributed a significant difference to the grouping both for the unweighted ( $p=0.001, \mathrm{R}: 0.67)$ and weighted ( $p=0.001, \mathrm{R}: 0.27)$. For the groups N13 and NICU (Figure 3C), there was a significant difference both for the 
unweighted ( $p=0.001, \mathrm{R}: 0.82)$ and weighted ( $p=0.008, \mathrm{R}: 0.36)$ UniFrac. These tests show that the N0 and DR groups were very different from each other in terms of bacterial composition, while in terms of relative abundances there were some overlaps. The N9 vs. NICU and N13 vs. NICU groups showed more overlaps in terms of bacterial composition and relative abundances.

A
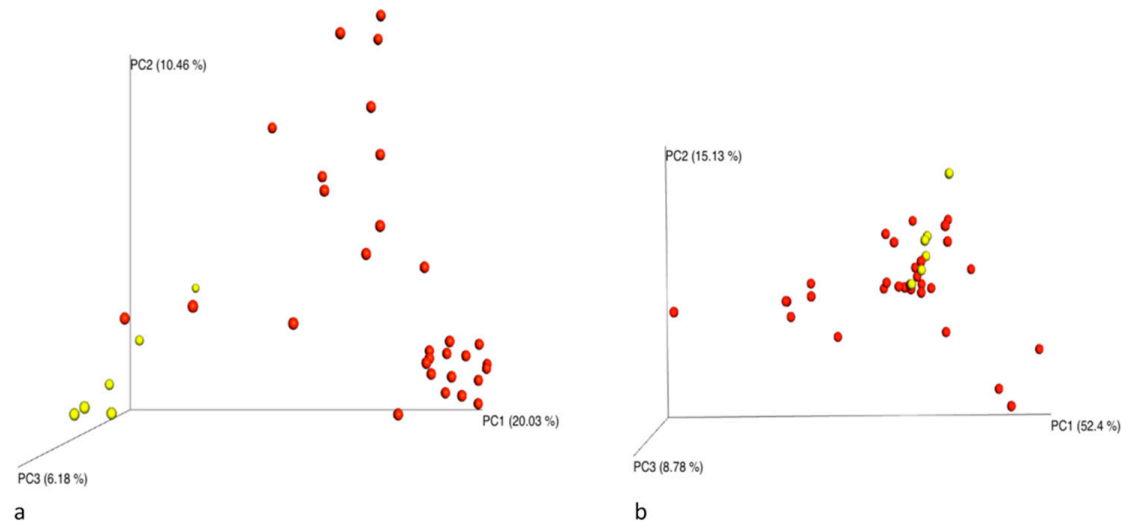

B
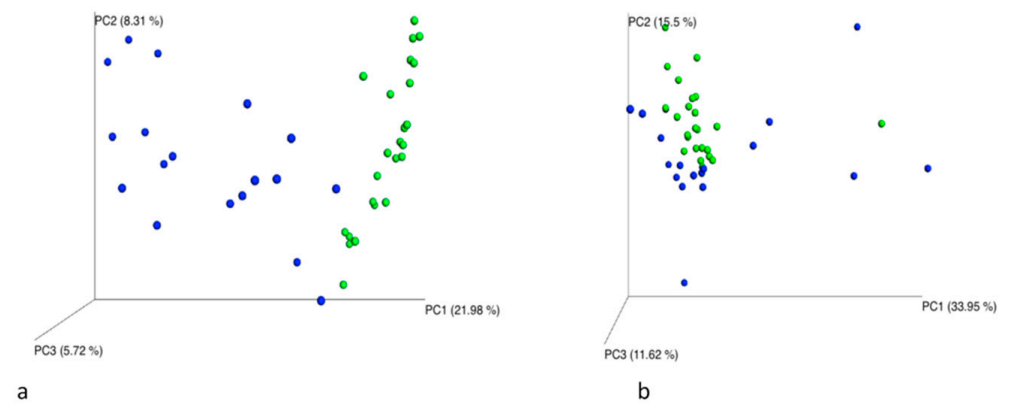

C
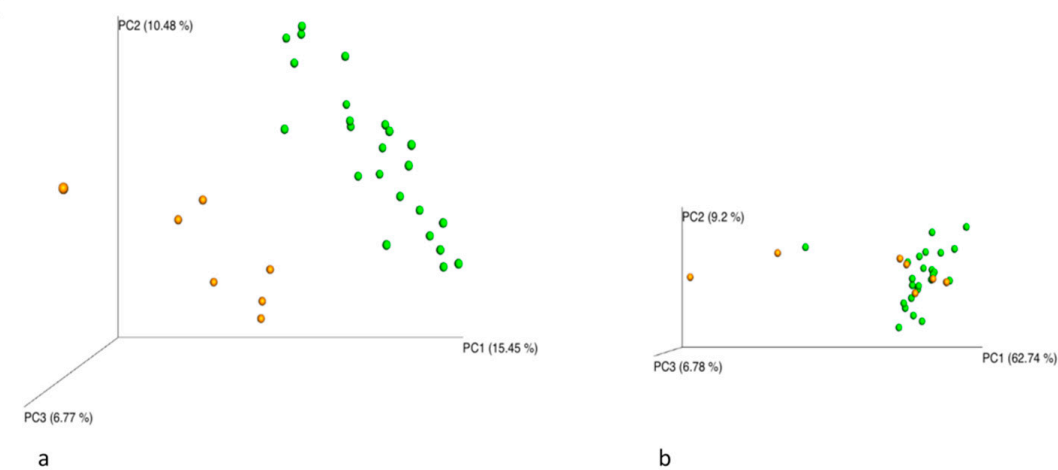

Figure 3. Emperor PCoA plot generated from the jackknifed_beta_diversity.py script of QIIME. Unweighted (a) and weighted (b) UniFrac-based PCoA, each dot represents a sample. (A) N0 vs. DR. N0 (red), DR (yellow). N0: nasal swabs collected at time of birth. DR: environmental samples from the Delivery Room. (B) N9 vs. NICU. N9 (blue), NICU (green). N9: nasal swabs collected after 9 days of permanence in NICU. NICU: environmental samples from the ward. (C) N13 vs. NICU. N13 (orange), NICU (green). N13: nasal swabs collected after 13 days of permanence in NICU. 
The bacterial composition of the selected surfaces was compared with that of the nasal swabs, to understand the significant source of infection, considering the mean of the relative abundances of each genus. Table 1 summarizes the bacteria found in the delivery and NICU rooms and colonizing the nasal microbiome of newborns. Notably, in the DR, Cutibacterium spp. represent the most frequent microorganisms found in the nose of newborns. On the other hand, in NICU, Staphylococcus spp. predominated both in N9 $(94 \%, 12 / 13)$ and in N13 groups (100\%, 7/7). Figure 4A shows the microbiome distribution of the DR in comparison with the nasal swabs of newborns of group N. Cutibacterium spp. was present at higher relative abundance (13\%) in nasal swab compared to other genera, and it was detected at higher values in the medical trolley $(23 \%)$ than the other points examined. Staphylococcus spp. showed a relative abundance of $6 \%$ in nasal swabs, this genus represented the primary contaminant of the floor of DR, with a relative abundance of $11 \%$. Lactobacillus spp. and Corynebacterium spp., both with a relative abundance of $4 \%$ in the beds' footboards, showed a rate of noise colonization of $6 \%$ and $2 \%$, respectively.

Table 1. Main bacterial genera of environment compared with nasal swabs. N0: nasal swabs collected at time of birth; N9: samples collected after 9 days of permanence in NICU. N13: sample collected after 13 days of permanence in NICU. Data are expressed as percentage of colonized patients for each genus.

\begin{tabular}{|c|c|c|c|c|}
\hline Main Bacterial Genera of DR & $\begin{array}{c}\text { No } \\
\text { Colonized Patients } \\
(\%)\end{array}$ & $\begin{array}{c}\text { Main Bacterial Genera } \\
\text { of NICU }\end{array}$ & $\begin{array}{c}\text { N9 } \\
\text { Colonized Patients } \\
(\%)\end{array}$ & $\begin{array}{c}\text { N13 } \\
\text { Colonized Patients } \\
(\%)\end{array}$ \\
\hline Staphylococcus spp. & $53 \%$ & Staphylococcus spp. & $94 \%$ & $100 \%$ \\
\hline Streptococcus spp. & $53 \%$ & Streptococcus spp. & $61 \%$ & $71 \%$ \\
\hline Cutibacterium spp. & $83 \%$ & Cutibacterium spp. & $33 \%$ & $14 \%$ \\
\hline Corynebacterium spp. & $40 \%$ & Corynebacterium spp. & $56 \%$ & $57 \%$ \\
\hline Escherichia-Shigella spp. & $33 \%$ & Escherichia-Shigella spp. & $61 \%$ & $100 \%$ \\
\hline Acinetobacter spp. & $67 \%$ & Acinetobacter spp. & $33 \%$ & $14 \%$ \\
\hline Pseudomonas spp. & $67 \%$ & Pseudomonas spp. & $33 \%$ & $14 \%$ \\
\hline Stenotrophomonas spp. & $23 \%$ & Stenotrophomonas spp. & $22 \%$ & $14 \%$ \\
\hline Rothia spp. & $17 \%$ & Rothia spp. & $17 \%$ & $19 \%$ \\
\hline Lactobacillus spp. & $20 \%$ & Lactobacillus spp. & $6 \%$ & $14 \%$ \\
\hline Chryseobacterium spp. & $3 \%$ & Chryseobacterium spp. & $6 \%$ & / \\
\hline Paracoccus spp. & $10 \%$ & Paracoccus spp. & / & / \\
\hline Actinomyces spp. & $10 \%$ & Enterobacter spp. & $22 \%$ & $29 \%$ \\
\hline Gemella spp. & $10 \%$ & Bifidobacterium spp. & / & / \\
\hline Bacillus spp. & $7 \%$ & Alishewanella spp. & / & / \\
\hline Neisseria spp. & $7 \%$ & Brevundimonas spp. & / & / \\
\hline Facklamia spp. & $3 \%$ & Gemmobacter spp. & / & / \\
\hline Empedobacter spp. & / & Empedobacter spp. & / & / \\
\hline Anaerococcus spp. & / & & & \\
\hline
\end{tabular}

\section{/: No detection.}

We then compared the environmental microbiome of the NICU with the nasal microbiome of newborns admitted to the ward and in the two consecutive follow-up points (N9 and N13) (Figure 4B). Staphylococcus spp. was found to have the highest relative percentages both in nasal swabs of N9 babies (37\%) and in the N13 group (44\%). The major NICU source appeared to be the footboard and floor (9\%), as well as the sink (10\%). Escherichia-Shigella spp. was detected in 29\% of the N13 group, and in the NICU was found mainly on the floor (4\%). Streptococcus spp. had similar values in noses (N9: 8\%, N13: 5\%) and surfaces (floor and sink: 5\%, footboard 8\%). Corynebacterium spp., present in all three surfaces of the NICU in percentages less than 3\%, had an average relative abundance of $5 \%$ in the N9 group and 11\% in the N13 group. Other bacterial genera present in both nasal swabs and the NICU environment were: Pseudomonas spp. (S: 3\%, footboard: 7\%, floor: 2\%, sink 5\%) and Stenotrophomonas spp. (N13: 4\%, footboard: 3\%, sink: 1\%). 
A

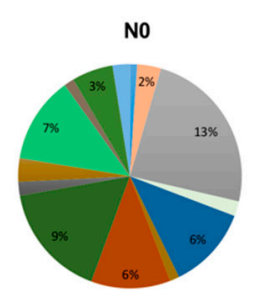

B
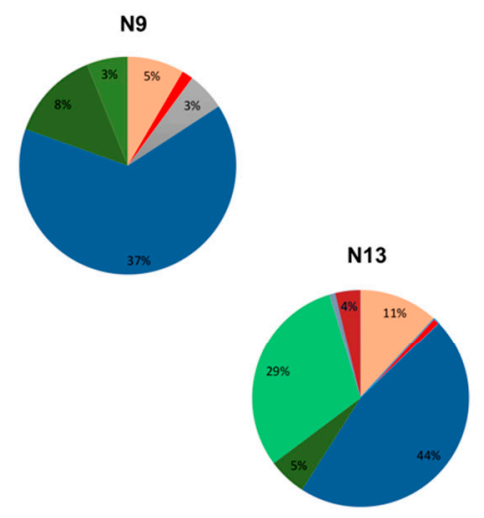

- Actinomyces spp.

- Cutibacterium spp.

- Empedobacter spp.

- Facklamia spp.

- Anaerococcus spp.

- Escherichia-Shigella spp.

- Stenotrophomonas spp.

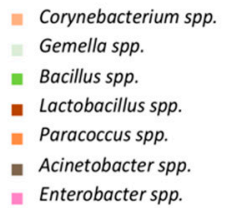

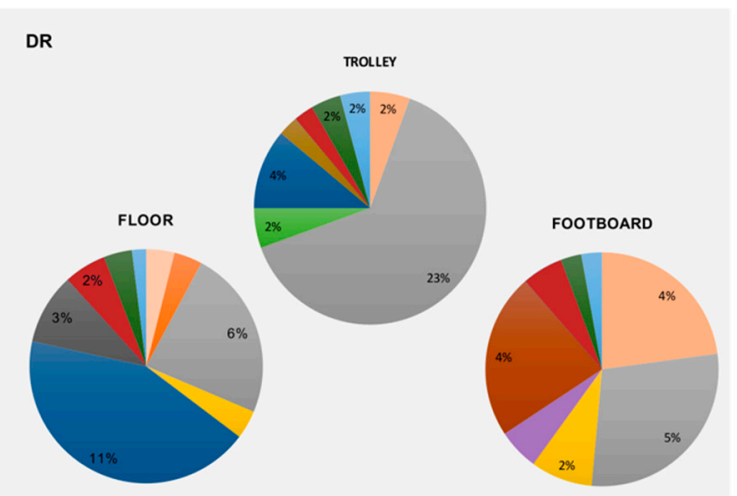

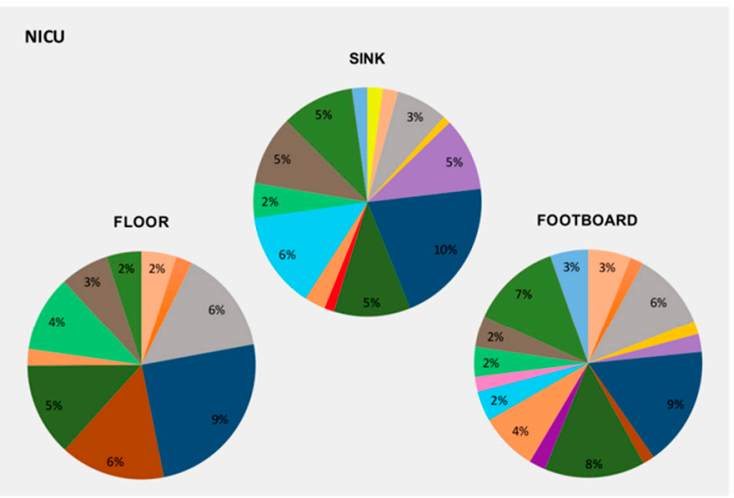

- Rothia spp.

Chryseobacterium spp.

- Staphylococcus spp.

- Streptococcus spp.

- Neisseria spp.

- Pseudomonas spp.

- Gemmobacter spp.

Figure 4. The predominant bacterial communities of nasal swabs from newborns in comparison with the environmental ones. Results were obtained by NGS. Data are expressed as mean relative abundance values. (A) N0 vs. DR. N0: nasal swabs collected at time of birth; DR: environmental samples of delivery room divided into type of surface (floor, footboard, and trolley). (B) N9 and N13 vs. NICU. N9: samples collected after 9 days of permanence in NICU. N13: sample collected after 13 days of permanence in NICU; NICU: environmental samples of NICU divided into type of surface (floor, footboard, and sink).

\subsection{Microarray Analysis Results}

The results obtained by NGS were confirmed by the qPCR microarray analyses, which allowed the identification of bacteria up to species level, evidencing a progressive increase of positivity for specific microorganisms in the nasal swabs of newborns hosted in the NICU ward over time (N13 > N9 > N0). Within the genus Staphylococcus, the main species were aureus (N0: 3\%, N9: 33\%, N13: 43\%) and epidermidis (N0: 27\%, N9: 89\%, N13: $100 \%)$. Instead, within the genus Streptococcus, the most frequently detected species were pneumoniae, infantis, oralis, and salivarius, with higher identification rates in the N13 group. This method also allowed the identification of the fungus Candida albicans in group N9 $(6 \%)$ and N13 (43\%), but not in group N0. Other microorganisms increasing in N9 and N13 compared to group N0 included Enterococcus faecalis (N0, 20\%; N9, 55\%; N13, 85\%), Escherichia-Shigella (N0, 20\%; N9, 38\%; N13, 71\%), Klebsiella pneumoniae (N0, 0\%; N9, 44\%; N13, 85\%), K. oxytoca/Enterobacter cloacae (N0, 23\%; N9, 67\%; N13, 86\%), Pseudomonas 
aeruginosa (N0,7\%; N9, 38\%; N13,43\%), and, although to a less extent, Acinetobacter baumannii (N0, 13\%; N9, 11\%; N13, 28\%).

Comparative quantitation between newborn groups evidenced significant increases over time (N13 vs. N0) of S. epidermidis, K. pneumoniae/oxytoca, Escherichia-Shigella (about $3 \operatorname{logs} ; p<0.01)$, E. faecalis, S. aureus, P. aeruginosa, S. pneumonia/infantis/oralis/salivarius, and C. albicans (between 1 and 2 logs, $p<0.01$ ). Interestingly, the results of microarray analysis performed on environmental samples of DR and NICU rooms showed that the highest contamination levels were ascribable to S. epidermidis (2200 genome copies per $100 \mathrm{~cm}^{2}$ ) and K. pneumoniae/Enterobacter (1833 genome copies per $100 \mathrm{~cm}^{2}$ ), followed by P. aeruginosa $\left(186.7\right.$ copies $\left./ 100 \mathrm{~cm}^{2}\right)$, S. aureus $\left(153.3\right.$ copies $\left./ 100 \mathrm{~cm}^{2}\right)$, Enterococcus faecalis/faecium ( 47.5 copies $/ 100 \mathrm{~cm}^{2}$ ), and A. baumannii $\left(20.3\right.$ copies $\left./ 100 \mathrm{~cm}^{2}\right)$. On the contrary, the other species were less represented. Contamination levels were higher on the floor and sink compared to bed footboard (not shown). In the DR, the level of contamination was generally lower compared to the NICU ward, including essentially Staphylococci (S. epidermidis, 310 copies $/ 100 \mathrm{~cm}^{2}$; S. aureus 3.3 copies $\left./ 100 \mathrm{~cm}^{2}\right)$ and E. faecium $\left(13.4\right.$ copies $\left./ 100 \mathrm{~cm}^{2}\right)$, mainly present on the floor and sink.

To further characterize the environmental and nasal microbiome, we performed the analysis of the population resistome of both contaminating environmental microbiome and microbiome colonizing newborns' nose. The analysis was carried out by a qPCR microarray, simultaneously detecting 84 different $R$ genes. The results are summarized in Figure 5. Interestingly, the comparative analysis of the resistome of the newborns hosted in the NICU ward evidenced a progressive enrichment of strains harbouring $\mathrm{R}$ genes over time (Figure 5 and Table 2). While at birth, no R genes were detectable in the newborn nasal microbiome, after 9 (N9 group) and 13 days (N13 group) of hospitalization, the analysis revealed, respectively, the appearance and the increase of several $\mathrm{R}$ genes, most of which were also present in the NICU environment.

Table 2. Presence of AMR-associated genes in the nasal microbiota of newborns in NICU ward.

\begin{tabular}{cccc}
\hline R Genes & N0 Group & N9 Group & N13 Group \\
\hline AAC(6)-lb-cr & - & + & - \\
SHV group & - & + & + \\
ACT 5/7 group & - & + & + \\
CMY-10 group & - & - & + \\
LAT & - & - & + \\
MOX & - & + & + \\
OXA-50 group & - & - & + \\
QnrS & - & - & + \\
ermB & - & + & + \\
ermC & - & - & + \\
mefA & - & + & + \\
msrA & - & + & + \\
oprj & - & + & + \\
oprm & - & - & + \\
tetA & - & - & + \\
vanC & - & + & + \\
mecA/spa & - & + & + \\
\hline
\end{tabular}

-: No detection of the resistance gene; +: Presence of the resistance gene. 

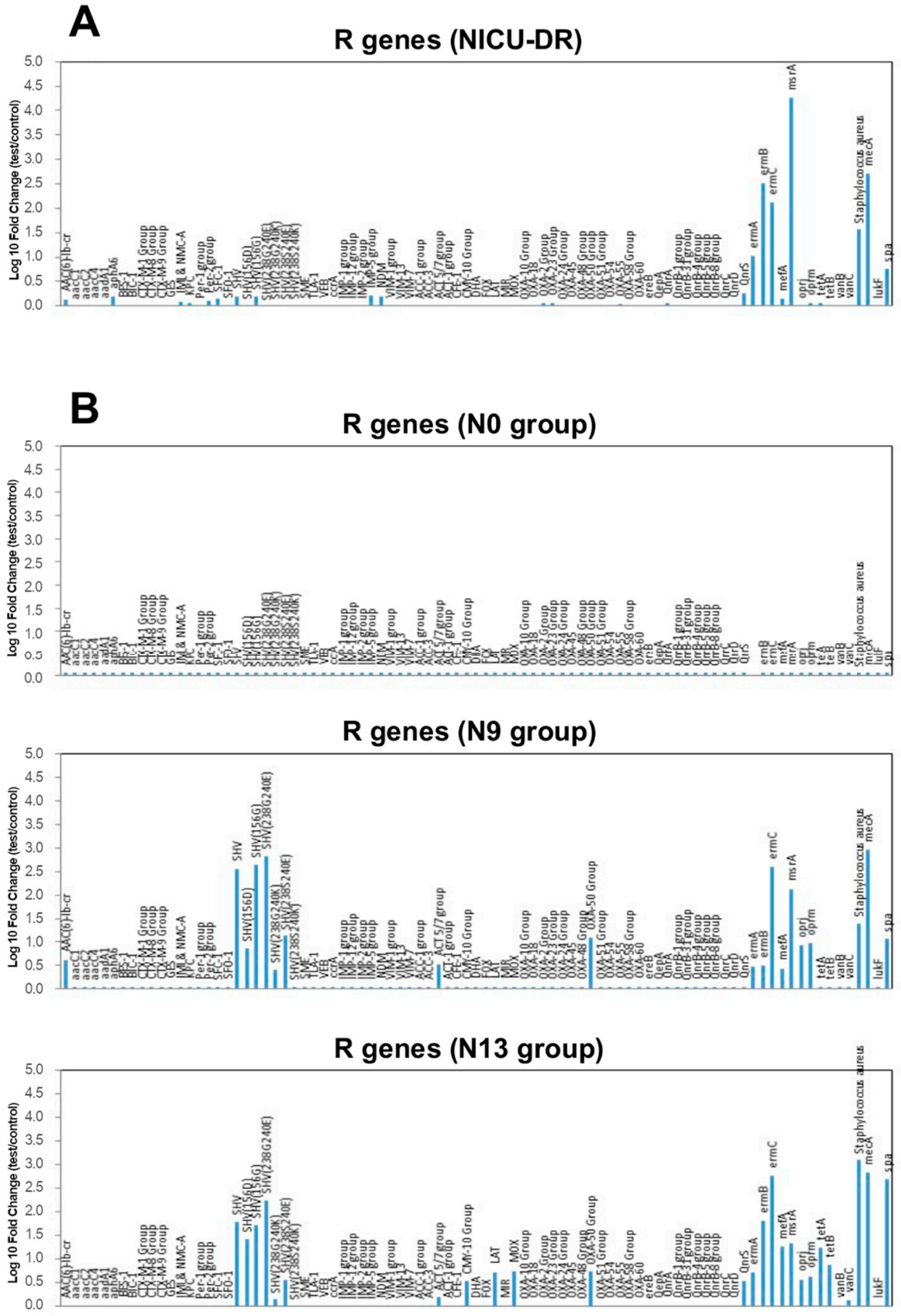

Figure 5. Resistome characterization of the microbial population contaminating NICU surfaces. Results were obtained by qPCR microarray as described in Methods and are expressed as $\log _{10}$ fold change of each detected R gene, compared with the negative controls (NTC). The plotted data represent the mean values of duplicate samples obtained in two environmental samplings for NICU environmental duplicate sampled points (A) and for nasal swabs of N0, N9, and N13 newborn groups (B).

\section{Discussion}

This study investigated the potential influence of the environment microbiome on preterm newborns' colonization admitted to the NICU. Nasal swabs of newborns were 
collected routinely as part of the HAIs prevention and control system of the hospital. Given the fragility of the patients, no further practices were introduced for the collection of swabs from other anatomical sites. The nasal cavities represent a highly accessible airway microbial community that recently was confirmed to have a pivotal role in human health and, to date, few studies focused on the microbiome of the nostrils of newborns [46,47]. The colonization of the upper respiratory tract is the gateway for lower tract infections. For example, in infants' nasopharyngeal colonization with Moraxella spp. and Haemophilus spp. early in life is linked to the development of lower respiratory tract infections and consecutive atopic disease and future asthma [48]. Additionally, nasopharyngeal colonization with S. pneumoniae showed to be an important prerequisite to severe respiratory pneumococcal diseases such as sepsis, meningitis, and pneumonia [49]. Furthermore, the respiratory microbiota tract may have a role in the development respiratory tract and in shaping the local neonatal immune system [50].

The importance of the role of the mother's microbiome in the colonization of the newborn is recognized, not only of the vaginal one, but also of the intestinal, cutaneous, and oral one [51-54]. Thus, besides the environmental contribution, in this study we also evaluated the contribution of mother's vaginal bacteria in the colonization of the nasal microbiome of newborns. The surveillance analysis of the nose microbiome composition of newborns during the first hour after birth showed the presence of numerous bacterial taxa, likely derived from the mother's resident vaginal microflora and bacteria colonizing the DR environment. The nasal cavities of newborns harboured bacterial species such as Lactobacillus spp. and Streptococcus spp. from the vaginal origin, and Cutibacterium spp., Staphylococcus spp. Corynebacterium spp., Acinetobacter spp., Pseudomonas spp., Stenotrophomonas spp., and Rothia spp. from DR environment surfaces, demonstrating how these bacteria begin part of the human microbiome during the first minutes after birth and showed a dynamic profile associated with the time of hospitalization.

In particular, our study showed that the frequency of colonization by specific opportunistic pathogenic genera responsible for HAIs [55-57], becomes predominant of nose microbiome with the time of permanence in intensive care. The quantitative molecular methods employed allowed the detection of microorganisms in higher percentages in the N13 group compared to the N0 group both in terms of the number of colonized patients, microorganism amount and relative abundance. This trend was observed in particular for Staphylococcus, both aureus and epidermidis species, Streptococcus spp., Escherichia-Shigella spp., K. pneumoniae, and K. oxytoca/E. cloacae species. These bacterial genera were among those most frequently detected on the NICU floor and bed platforms, at higher contamination levels.

To note, bacteria belonging to the genus Staphylococcus spp., detected in all N13 group patients, with the highest percentage of relative abundance when compared to the N9 and N13 groups, and the amount of the other bacteria identified, are responsible for the majority of late-onset infections in VLBW babies [56]. Methicillin-resistant S. aureus (MRSA), detected on the surfaces of the NICU and the nasal swabs of newborns after admission to the ward, is associated with significant mortality and morbidity, especially in very immature preterm neonates $[58,59]$. Approximately one out of five neonates colonized with MRSA may develop an infection, as prematurity has been identified to be the leading risk factor for MRSA colonization and subsequent infections [60]. MRSA colonized patients can shed into the environment their strain of Staphylococcus [61], which can survive in hospital dust for up to a year resisting desiccation [62]. Additionally, S. epidermidis has emerged as a predominant pathogen of neonatal late-onset sepsis in VLBW infants [63].

Similarly, C. albicans, which was not present in the nose of newborns at the time of birth, was instead detected after their admission in NICU. Candida infections contracted by nosocomial transmission [64-66] are one of the main cause of late-onset sepsis in VLBW preterm neonates [67].

Consistent with potent contamination of newborns by environmental and potentially pathogenic nosocomial microbes, the analysis of nasal bacteria resistome evidenced the 
absence of resistance $(R)$ genes at detectability levels in the infants at the time of birth. On the contrary, we detected several R genes after admission to the NICU, and they increased with the prolonged hospitalization. Most of these genes were also detected in the microbial population contaminating the ward environment, including beta-lactam resistance genes $(\mathrm{SHV})$, quinolone resistance genes $(\mathrm{QnrS})$, and macrolide resistance genes (ermA, ermB, ermC, mefA, msrA). Based on kinetic of newborns colonization by environmental microorganisms $[68,69]$, based on the so-called paradigm of the "sterile womb", with a few taxa present at birth, the absence of $\mathrm{R}$ genes at time 0 and their appearance at 9 and 13 days after birth are compatible with the arrival of resistant strains from the environment and their proliferation/colonization in the nasal cavities of the babies.

This data provides further support of environmental microorganisms colonization of the newborn patients, highlighting, once again, the role of the hospital environment as a source of potentially pathogenic ad drug-resistant microorganisms, with consequent difficulties in their containment and the management of the correlated infections [70,71].

The results of this study highlight the importance of active monitoring of the environmental microbial contamination, using high sensitivity molecular methods that guarantee the characterization of microbial communities in the wards as well as in admitting patients, allowing to understand the transmission routes through which environmental microbes can come in contact with patients. The ward contamination can contribute to the transmission of HAIs, and that environmental monitoring and microbiological surveillance can reduce the rate of infections [72]. The knowledge of the main microbial species, as well as the intrinsic genes of antibiotic resistance patterns, can guide more effective therapeutic treatment $[73,74]$.

Furthermore, data from the screening of surfaces should be evaluated to generate increased or targeted cleaning approaches to prevent possible outbreaks [75] suggesting the implementation of new strategies for surface sanitizing. Most of the detergents used in sanitizing hospitals, based on chemical germicides, are not able to stably decontaminate the surfaces, as they cannot counteract the recontamination phenomena, ultimately responsible for the persistence of microorganisms in the environment [76,77]. Furthermore, chemicalbased disinfectants, such as those based on chlorine also used for the sanitization of the surfaces of the hospital involved in this study, have a high environmental impact, and some of them have been reported to favour the selection of resistant strains, an undesirable side effect [78-80]. Among the proposed innovative methods, a sanitation system allowing colonization by benign microbes rather than potential pathogens appears potentially attractive, as successfully reported in a recent Italian multicentre study [81,82].

In conclusion, despite the pilot features of our study, the results show that environmental hospital microbes (including drug-resistant strains) detected on ward surfaces can reach the respiratory tract of preterm newborns starting from birth and increasing in the NICU. The data from this observational study suggest that hospital surface microbiota could be transmitted by contact, and it might also be transported, perhaps by air particles, even to respiratory mucosae or other profound tissues.

Based on these observations, we think that monitoring the hospital environment should be a mandatory aspect of infection prevention, control strategies, and suggests that molecular methodologies are a suitable tool to reach the goal of controlling potentially pathogenic contamination.

\section{Materials and Methods}

\subsection{Patients and Samples}

As part of the hospital infection control protocol, from November 2018 to January 2019, a total of 55 nasal swabs were collected from preterm infants, attending the NICU at the IRCCS Burlo Garofolo Hospital in Trieste, Italy, regardless of their clinical condition. The study time-course of sample collection included: 30 swabs at the time of birth (group N0), 18 after 9 days (group N9), and 7 after 13 days of permanence in the NICU ward (group N13) depending on the health status of the newborns. N9 and N13 groups include 
the newborns that from N0 group were hospitalized for 9 and 13 days, respectively. At the same time, four randomized rooms in the NICU and one in the DR were selected for environmental surveillance following a standard protocol [81]. A total of 24 samples from critical points, including the floor, footboard, and sink, were gathered from the NICU, while 6 were collected from floor, footboard, and hospital trolley of the DR. Sampling was performed twice and analysed by NGS and by a real time quantitative PCR microarray approach. Twenty vaginal swabs were additionally collected from pregnant women before giving birth in the DR.

\subsection{Nasal Swab Collection}

Anterior nasal swabs were collected by nurses and put in a sterile medium, using eSwabs and liquid amies transportation medium (Copan, Brescia, Italy). Immediately after collection, swabs were sent to the laboratory and stored at $-80{ }^{\circ} \mathrm{C}$ until analysis.

\subsection{Environmental Sampling}

Sterile rayon swabs (Copan, Brescia, Italy) were premoistened in a sterile saline solution and used to collect a surface of $100 \mathrm{~cm}^{2}$ delimited by a sterile $10 \times 10 \mathrm{~cm}$ disposable plastic template (Copan, Brescia, Italy). Swabs were then put in $300 \mu \mathrm{L}$ of sterile saline solution and stored at $-80^{\circ} \mathrm{C}$ until analysis. The samples were collected in duplicate and extracted separately.

\subsection{Vaginal Swabs Collection}

Samples were collected using a $200 \mathrm{~mm}$ polyethylene Cervix brush device (Rovers Medical Devices B.V., The Netherlands) under speculum examination, by a $360^{\circ}$ rotation of the brush. Samples were then suspended in $1.5 \mathrm{~mL}$ of TE buffer and stored at $-80^{\circ} \mathrm{C}$ until analysis.

\subsection{Next Generation Sequencing Analysis}

\subsubsection{DNA Extraction}

Before being processed, all samples were defrosted and vortexed. The DNA extraction was performed from $300 \mu \mathrm{L}$ of the samples at a final elution volume of $100 \mu \mathrm{L}$ for nasal and vaginal swabs, and in $50 \mu \mathrm{L}$ for the environmental samples, using the automatic extractor Maxwell CSC DNA Blood Kit (Promega, Madison, WI, USA), according to the manufacturer's instruction.

\subsubsection{Library Preparation}

The 16S rRNA gene (V3 region) was sequenced to characterize the composition of bacterial communities of samples. Alongside, negative controls, including no template controls (NTC), were processed. In addition, the swabs and reagents used for sampling were tested for the presence of bacterial DNA, confirming them to be sterile. A real time quantitative EvaGreen ${ }^{\circledR}$ dye (Fisher Molecular Biology, Waltham, MA, USA) PCR was performed to amplify several bacterial species, using the U534R primer and the degenerated primer 27FYM (5'-AGR GTT YGA TYM TGG CTC AG-3'), targeting the V1-V3 region, $(500 \mathrm{bp})$. A nested PCR was subsequently carried out with the primers B338F_P1adaptor (B338F 5'-ACTCCTACGGGAGGCAGC-3') and U534R_A_barcode (U534R 5'ATTACCGCGGCTGCTGG-3'), targeting the V3 region (200 bp) of the $16 \mathrm{~S}$ rRNA gene, with a different barcode for each sample attached to the reverse primer [83].

The PCR reactions were performed using the Kapa HiFi Hotstart ready mix 2X (Kapa Biosystems, Massachusetts, MA, USA) and BSA $400 \mathrm{ng} / \mu \mathrm{L}$. We did this according to these conditions: initial denaturation step of $95^{\circ} \mathrm{C}$ for $5 \mathrm{~min}$, followed by a denaturation step at $95^{\circ} \mathrm{C}$ for $30 \mathrm{~s}$, annealing at $59^{\circ} \mathrm{C}(\mathrm{V} 1-\mathrm{V} 3 \mathrm{PCR}) / 57^{\circ} \mathrm{C}$ (V3 PCR) for $30 \mathrm{~s}$, and extension at $72^{\circ} \mathrm{C}$ for $45 \mathrm{~s}$ with maximum of 27 cycles for the V1-V3 PCR and a maximum of 13 cycles for the V3 PCR. Final extension step of $10 \mathrm{~min}$ at $72{ }^{\circ} \mathrm{C}$. The correct size of the amplicon (260 bp) was assessed on a 2\% agarose gel. 
The quantification of the amount of DNA was performed using a Qubit ${ }^{\circledR} 2.0$ Fluorimeter (Invitrogen, Carlsbad, CA, USA), and $100 \mathrm{ng}$ of PCR from each sample was mixed to generate the pooled library and diluted to a concentration of $100 \mathrm{pM}$, according to manufacturer's instruction. Ion PGM Hi-Q View OT2 200 kit was used to prepare the template on the Ion OneTouch ${ }^{\mathrm{TM}} 2$ System (Life Technologies, Gran Island, New York, NY, USA). Sequencing was performed with the Ion PGM ${ }^{\mathrm{TM}}$ System technology using the Ion PGM Hi-Q View sequencing kit (Life Technologies, New York, NY, USA).

\subsubsection{Data Processing}

The sequence data were processed using Quantitative Insights Into Microbial Ecology (QIIME 2 2020.2) [84]. High quality sequences $(Q>25)$ were demultiplexed and filtered with default parameters, except for the length $(150 \mathrm{bp})$. Any sequence with ambiguous bases or a homopolymer length $>8$ was removed. Further analysis was performed on a random subset of 2000 reads/sample. Taxonomy assignment at the genus level was performed against the reference taxonomy database SILVA V.132 [85] with a similarity threshold of $97 \%$.

\section{6. qPCR Analyses}

\subsubsection{DNA Extraction}

Frozen environmental samples were thawed and vortexed to detach cells from swabs, Total DNA was extracted by a commercial kit (Gene All, Tema Ricerca, Italy), following the manufacturer's instruction adjusted to optimize the extraction from Gram-positive bacteria, as already described [86].

\subsubsection{Microarray Analysis}

Characterization of the microbial contamination at the species level was performed by a customized array assessing simultaneously the presence of 22 bacterial and mycetes species, among the most frequently involved in HAIs as previously described $[45,86]$. Acinetobacter baumanii, Aspergillus fumigatus, Candida albicans, Citrobacter freundii, Clostridium difficile, Clostridium perfrigens, Enterobacter cloacae/Klebsiella oxytoca, Enterococcus faecalis, Enterococcus faecium, Escherichia coli, Klebsiella pneumoniae, Proteus vulgaris and mirabilis, Pseudomonas aeruginosa, Staphylococcus aureus and epidermidis, Streptococcus agalactiae, anginosus, prneumoniae, pyogenes, infantis/oralis, and salivarius (Qiagen, Hilden, Germany). A pan-bacterial (panB) and pan-mycetes (panM) quantification, as well as a positive amplification control (PPC) and negative no template control (NTC) were also included in the array. The use of a real-time microarray, together with the normalization based on $\mathrm{panB} /$ panM results, allowed relative quantification of each parameter.

The analysis of microbial contamination at the environmental level was performed by a similar customized qPCR microarray, including all the previously mentioned species except for Streptococci (Qiagen, Hilden, Germany).

Characterization of antimicrobial resistance (AMR) genes of the contaminant population was obtained by a microarray detecting and quantifying simultaneously 84 different AMR genes (Qiagen, Hilden, Germany), as previously described [45,81,82,87].

\subsection{Statistical Analyses}

Statistical analyses were performed with QIIME 2 (2020.2). Beta diversity (between sample-diversity comparison) was assessed with weighted and unweighted UniFrac distance matrices [88] and presented with principal coordinates analysis (PCOA). Analyses of Similarities (ANOSIM) and Kruskal-Wallis tests were performed to compare the community composition in the group considered (N0-N9-N13, N0-AP, N9-AT, N13-AT), assuming a statistically significant FDR $p$ value of at least $<0.05$.

For microarray results, statistical analyses were performed using parametric (Student's $t$ test) and non-parametric (Mann-Whitney) tests, assuming a statistically significant $p$ 
value of at least $<0.05$. Bonferroni correction for multiple comparisons was applied for the analysis of microarray data (a $p c$ value $<0.05$ was considered significant).

Author Contributions: Conceptualization, M.C. and E.C.; Data curation, M.D. and I.S.; Formal analysis, G.C.; Funding acquisition, S.M.; Investigation, C.C., M.D., I.S., and G.P.; Methodology, E.C.; Resources, A.M. and F.M.R.; Supervision, S.M.; Writing-original draft, C.C., M.C., and E.C.; Writing-review and editing, M.C. and E.C. All authors have read and agreed to the published version of the manuscript.

Funding: This study was supported by a grant (R.C. 18/17) from the Italian Ministry of Health and the Institute for Maternal and Child Health IRCCS Burlo Garofolo, Trieste, Italy.

Institutional Review Board Statement: Ethical review and approval were waived for this study due to the surveillance was part of the hospital infection control, and no patient personal information was collected.

Informed Consent Statement: Patient consent was waived due to the surveillance was part of the hospital infection control and no patient personal information was collected.

Data Availability Statement: The data presented in this study are available on request from the corresponding author.

Acknowledgments: The authors thank Martina Bradaschia for her editing contribution.

Conflicts of Interest: The authors declare no conflict of interest.

\section{References}

1. Plano, L.R.W. The Changing Spectrum of Neonatal Infectious Disease. J. Perinatol. 2010, 30, S16-S20. [CrossRef]

2. $\quad$ Resende, D.S.; Peppe, A.L.G.; dos Reis, H.; Abdallah, V.O.S.; Ribas, R.M.; Gontijo Filho, P.P. Late Onset Sepsis in Newborn Babies: Epidemiology and Effect of a Bundle to Prevent Central Line Associated Bloodstream Infections in the Neonatal Intensive Care Unit. Braz. J. Infect. Dis. 2015, 19, 52-57. [CrossRef]

3. Borghesi, A.; Stronati, M. Strategies for the Prevention of Hospital-Acquired Infections in the Neonatal Intensive Care Unit. J. Hosp. Infect. 2008, 68, 293-300. [CrossRef]

4. Bolat, F.; Uslu, S.; Bolat, G.; Comert, S.; Can, E.; Bulbul, A.; Nuhoglu, A. Healthcare-Associated Infections in a Neonatal Intensive Care Unit in Turkey. Indian Pediatr. 2012, 49, 951-957. [CrossRef] [PubMed]

5. Tawfik, D.S.; Sexton, J.B.; Kan, P.; Sharek, P.J.; Nisbet, C.C.; Rigdon, J.; Lee, H.C.; Profit, J. Burnout in the Neonatal Intensive Care Unit and Its Relation to Healthcare-Associated Infections. J. Perinatol. 2017, 37, 315-320. [CrossRef] [PubMed]

6. Kawagoe, J.Y.; Segre, C.A.M.; Pereira, C.R.; Cardoso, M.F.S.; Silva, C.V.; Fukushima, J.T. Risk Factors for Nosocomial Infections in Critically Ill Newborns: A 5-Year Prospective Cohort Study. Am. J. Infect. Control 2001, 29, 109-114. [CrossRef] [PubMed]

7. Larson, A.A.; Dinulos, J.G.H. Cutaneous Bacterial Infections in the Newborn. Curr. Opin. Pediatr. 2005, 17, 481-485. [CrossRef] [PubMed]

8. Borghesi, A.; Stronati, M.; Castagnoli, R.; Ioimo, I.; Achille, C.; Manzoni, P.; Tzialla, C. Novel Approaches to the Study of Neonatal Infections. Am. J. Perinatol. 2018, 35, 570-574. [CrossRef]

9. Zaidi, A.K.; Huskins, W.C.; Thaver, D.; Bhutta, Z.A.; Abbas, Z.; Goldmann, D.A. Hospital-Acquired Neonatal Infections in Developing Countries. Lancet 2005, 365, 1175-1188. [CrossRef]

10. Graham, P.L.; Morel, A.-S.; Zhou, J.; Wu, F.; Della-Latta, P.; Rubenstein, D.; Saiman, L. Epidemiology of Methicillin-Susceptible Staphylococcus Aureus in the Neonatal Intensive Care Unit. Infect. Control Hosp. Epidemiol. 2002, 23, 677-682. [CrossRef] [PubMed]

11. Raimundo, O.; Heussler, H.; Bruhn, J.B.; Suntrarachun, S.; Kelly, N.; Deighton, M.A.; Garland, S.M. Molecular Epidemiology of Coagulase-Negative Staphylococcal Bacteraemia in a Newborn Intensive Care Unit. J. Hosp. Infect. 2002, 51, 33-42. [CrossRef]

12. Nash, D.R.; Harman, J.; Wald, E.R.; Kelleher, K.J. Antibiotic Prescribing by Primary Care Physicians for Children with Upper Respiratory Tract Infections. Arch Pediatr. Adolesc. Med. 2002, 156, 1114-1119. [CrossRef] [PubMed]

13. Clark, R.H.; Bloom, B.T.; Spitzer, A.R.; Gerstmann, D.R. Empiric Use of Ampicillin and Cefotaxime, Compared with Ampicillin and Gentamicin, for Neonates at Risk for Sepsis is Associated with an Increased Risk of Neonatal Death. Pediatrics 2006, 117, 67-74. [CrossRef] [PubMed]

14. Hsieh, E.M.; Hornik, C.P.; Clark, R.H.; Laughon, M.M.; Benjamin, D.K.; Smith, P.B.; Best Pharmaceuticals for Children ActPediatric Trials Network. Medication Use in the Neonatal Intensive Care Unit. Am. J. Perinatol. 2014, 31, 811-821. [CrossRef] [PubMed]

15. Blaser, M.J. Antibiotic Use and Its Consequences for the Normal Microbiome. Science 2016, 352, 544-545. [CrossRef]

16. Hoskin-Parr, L.; Teyhan, A.; Blocker, A.; Henderson, A.J.W. Antibiotic Exposure in the First Two Years of Life and Development of Asthma and Other Allergic Diseases by 7.5 Yr: A Dose-Dependent Relationship. Pediatr. Allergy Immunol. 2013, $24,762-771$. [CrossRef] 
17. Kuppala, V.S.; Meinzen-Derr, J.; Morrow, A.L.; Schibler, K.R. Prolonged Initial Empirical Antibiotic Treatment is Associated with Adverse Outcomes in Premature Infants. J. Pediatr. 2011, 159, 720-725. [CrossRef]

18. Cantey, J.B.; Wozniak, P.S.; Sánchez, P.J. Prospective Surveillance of Antibiotic Use in the Neonatal Intensive Care Unit: Results from the SCOUT Study. Pediatr. Infect. Dis. J. 2015, 34, 267-272. [CrossRef] [PubMed]

19. Maragakis, L.L.; Perencevich, E.N.; Cosgrove, S.E. Clinical and Economic Burden of Antimicrobial Resistance. Expert Rev. Anti Infect. Ther. 2008, 6, 751-763. [CrossRef]

20. de Man, P.; Verhoeven, B.A.; Verbrugh, H.A.; Vos, M.C.; van den Anker, J.N. An Antibiotic Policy to Prevent Emergence of Resistant Bacilli. Lancet 2000, 355, 973-978. [CrossRef]

21. Cotten, C.M.; McDonald, S.; Stoll, B.; Goldberg, R.N.; Poole, K.; Benjamin, D.K.; National Institute for Child Health and Human Development Neonatal Research Network. The Association of Third-Generation Cephalosporin Use and Invasive Candidiasis in Extremely Low Birth-Weight Infants. Pediatrics 2006, 118, 717-722. [CrossRef]

22. Alexander, V.N.; Northrup, V.; Bizzarro, M.J. Antibiotic Exposure in the Newborn Intensive Care Unit and the Risk of Necrotizing Enterocolitis. J. Pediatr. 2011, 159, 392-397. [CrossRef] [PubMed]

23. Bailey, L.C.; Forrest, C.B.; Zhang, P.; Richards, T.M.; Livshits, A.; DeRusso, P.A. Association of Antibiotics in Infancy with Early Childhood Obesity. JAMA Pediatr. 2014, 168, 1063-1069. [CrossRef] [PubMed]

24. Silva, A.C.B.; Anchieta, L.M.; Lopes, M.F.d.P.; Romanelli, R.M.d.C.; Silva, A.C.B.; Anchieta, L.M.; Lopes, M.F.d.P.; Romanelli, R.M.d.C. Inadequate Use of Antibiotics and Increase in Neonatal Sepsis Caused by Resistant Bacteria Related to Health Care Assistance: A Systematic Review. Braz. J. Infect. Dis. 2018, 22, 328-337. [CrossRef] [PubMed]

25. Facciolà, A.; Pellicanò, G.F.; Visalli, G.; Paolucci, I.A.; Venanzi Rullo, E.; Ceccarelli, M.; D'Aleo, F.; Di Pietro, A.; Squeri, R.; Nunnari, G.; et al. The Role of the Hospital Environment in the Healthcare-Associated Infections: A General Review of the Literature. Eur. Rev. Med. Pharmacol. Sci. 2019, 23, 1266-1278. [CrossRef]

26. Tan, B.; Xian-Yang, X.; Zhang, X.; Peng-Zhou, X.; Wang, P.; Xue, J.; Ling-Huang, Y.; Li-Li, Y.; Fu-Qiu, J. Epidemiology of Pathogens and Drug Resistance of Ventilator-Associated Pneumonia in Chinese Neonatal Intensive Care Units: A Meta-Analysis. Am. J. Infect. Control 2014, 42, 902-910. [CrossRef] [PubMed]

27. Kung, Y.-H.; Hsieh, Y.-F.; Weng, Y.-H.; Lien, R.-I.; Luo, J.; Wang, Y.; Huang, Y.-C.; Chen, C.-L.; Chen, C.-J. Risk Factors of Late-Onset Neonatal Sepsis in Taiwan: A Matched Case-Control Study. J. Microbiol. Immunol. Infect. 2016, 49, 430-435. [CrossRef]

28. Greenberg, R.G.; Kandefer, S.; Do, B.T.; Smith, P.B.; Stoll, B.J.; Bell, E.F.; Carlo, W.A.; Laptook, A.R.; Sánchez, P.J.; Shankaran, S.; et al. Late-Onset Sepsis in Extremely Premature Infants: 2000-2011. Pediatr. Infect. Dis. J. 2017, 36, 774-779. [CrossRef]

29. El Manouni el Hassani, S.; Berkhout, D.J.C.; Niemarkt, H.J.; Mann, S.; de Boode, W.P.; Cossey, V.; Hulzebos, C.V.; van Kaam, A.H.; Kramer, B.W.; van Lingen, R.A.; et al. Risk Factors for Late-Onset Sepsis in Preterm Infants: A Multicenter Case-Control Study. NEO 2019, 116, 42-51. [CrossRef]

30. Tsai, M.-H.; Hsu, J.-F.; Chu, S.-M.; Lien, R.; Huang, H.-R.; Chiang, M.-C.; Fu, R.-H.; Lee, C.-W.; Huang, Y.-C. Incidence, Clinical Characteristics and Risk Factors for Adverse Outcome in Neonates with Late-Onset Sepsis. Pediatr. Infect. Dis. J. 2014, 33 , e7-e13. [CrossRef]

31. Cantey, J.B.; Milstone, A.M. Bloodstream Infections: Epidemiology and Resistance. Clin. Perinatol. 2015, 42, 1-16. [CrossRef] [PubMed]

32. Bizzarro, M.J.; Raskind, C.; Baltimore, R.S.; Gallagher, P.G. Seventy-Five Years of Neonatal Sepsis at Yale: 1928-2003. Pediatrics 2005, 116, 595-602. [CrossRef]

33. Lee, P.-L.; Lee, W.-T.; Chen, H.-L. Ventilator-Associated Pneumonia in Low Birth Weight Neonates at a Neonatal Intensive Care Unit: A Retrospective Observational Study. Pediatr. Neonatol. 2017, 58, 16-21. [CrossRef] [PubMed]

34. McGirt, M.J.; Zaas, A.; Fuchs, H.E.; George, T.M.; Kaye, K.; Sexton, D.J. Risk Factors for Pediatric Ventriculoperitoneal Shunt Infection and Predictors of Infectious Pathogens. Clin. Infect. Dis. 2003, 36, 858-862. [CrossRef]

35. Kawanishi, F.; Yoshinaga, M.; Morita, M.; Shibata, Y.; Yamada, T.; Ooi, Y.; Ukimura, A. Risk Factors for Ventilator-Associated Pneumonia in Neonatal Intensive Care Unit Patients. J. Infect. Chemother. 2014, 20, 627-630. [CrossRef] [PubMed]

36. Pople, I.K.; Bayston, R.; Hayward, R.D. Infection of Cerebrospinal Fluid Shunts in Infants: A Study of Etiological Factors. J. Neurosurg. 1992, 77, 29-36. [CrossRef] [PubMed]

37. Khan, H.A.; Baig, F.K.; Mehboob, R. Nosocomial Infections: Epidemiology, Prevention, Control and Surveillance. Asian Pac. J. Trop. Biomed. 2017, 7, 478-482. [CrossRef]

38. Talon, D.; Excoffon, L.; Tiv, M.; Pinçon, A.; Gbaguidi-Haoré, H.; Bertrand, X. Environmental Reservoirs of Meticillin Resistant Staphylococcus Aureus in Patients' Rooms: Potential Impact on Care Practices. Br. J. Infect. Control 2008, 9, 10-14. [CrossRef]

39. Chandrashekar, M.R.; Rathish, K.C.; Nagesha, C.N. Reservoirs of Nosocomial Pathogens in Neonatal Intensive Care Unit. J. Indian Med. Assoc. 1997, 95, 72-74.

40. Newman, M.J. Neonatal Intensive Care Unit: Reservoirs of Nosocomial Pathogens. West Afr. J. Med. 2002, 21, 310-312. [CrossRef]

41. Kramer, A.; Schwebke, I.; Kampf, G. How Long Do Nosocomial Pathogens Persist on Inanimate Surfaces? A Systematic Review. BMC Infect. Dis. 2006, 6, 130. [CrossRef] [PubMed]

42. Bokulich, N.A.; Mills, D.A.; Underwood, M.A. Surface Microbes in the Neonatal Intensive Care Unit: Changes with Routine Cleaning and over Time. J. Clin. Microbiol. 2013, 51, 2617-2624. [CrossRef] [PubMed]

43. Brooks, B.; Firek, B.A.; Miller, C.S.; Sharon, I.; Thomas, B.C.; Baker, R.; Morowitz, M.J.; Banfield, J.F. Microbes in the Neonatal Intensive Care Unit Resemble Those Found in the Gut of Premature Infants. Microbiome 2014, 2, 1. [CrossRef] 
44. Ellington, M.J.; Ekelund, O.; Aarestrup, F.M.; Canton, R.; Doumith, M.; Giske, C.; Grundman, H.; Hasman, H.; Holden, M.T.G.; Hopkins, K.L.; et al. The Role of Whole Genome Sequencing in Antimicrobial Susceptibility Testing of Bacteria: Report from the EUCAST Subcommittee. Clin. Microbiol. Infect. 2017, 23, 2-22. [CrossRef]

45. Comar, M.; D’Accolti, M.; Cason, C.; Soffritti, I.; Campisciano, G.; Lanzoni, L.; Bisi, M.; Volta, A.; Mazzacane, S.; Caselli, E. Introduction of NGS in Environmental Surveillance for Healthcare-Associated Infection Control. Microorganisms 2019, 7, 708. [CrossRef]

46. Man, W.H.; de Steenhuijsen Piters, W.A.A.; Bogaert, D. The Microbiota of the Respiratory Tract: Gatekeeper to Respiratory Health. Nat. Rev. Microbiol. 2017, 15, 259-270. [CrossRef]

47. Palmu, A.A.; Ware, R.S.; Lambert, S.B.; Sarna, M.; Bialasiewicz, S.; Seib, K.L.; Atack, J.M.; Nissen, M.D.; Grimwood, K. Nasal Swab Bacteriology by PCR during the First 24-Months of Life: A Prospective Birth Cohort Study. Pediatr. Pulmonol. 2019, 54, 289-296. [CrossRef]

48. Teo, S.M.; Mok, D.; Pham, K.; Kusel, M.; Serralha, M.; Troy, N.; Holt, B.J.; Hales, B.J.; Walker, M.L.; Hollams, E.; et al. The Infant Nasopharyngeal Microbiome Impacts Severity of Lower Respiratory Infection and Risk of Asthma Development. Cell Host Microbe 2015, 17, 704-715. [CrossRef]

49. Bogaert, D.; de Groot, R.; Hermans, P. Streptococcus Pneumoniae Colonisation: The Key to Pneumococcal Disease. Lancet Infect. Dis. 2004, 4, 144-154. [CrossRef]

50. Olszak, T.; An, D.; Zeissig, S.; Vera, M.P.; Richter, J.; Franke, A.; Glickman, J.N.; Siebert, R.; Baron, R.M.; Kasper, D.L.; et al. Microbial Exposure during Early Life Has Persistent Effects on Natural Killer T Cell Function. Science 2012, 336, 489-493. [CrossRef]

51. Nuriel-Ohayon, M.; Neuman, H.; Koren, O. Microbial Changes during Pregnancy, Birth, and Infancy. Front. Microbiol. 2016, 7, 1031. [CrossRef]

52. Underwood, M.A.; Sohn, K. The Microbiota of the Extremely Preterm Infant. Clin. Perinatol. 2017, 44, 407-427. [CrossRef]

53. Ferretti, P.; Pasolli, E.; Tett, A.; Asnicar, F.; Gorfer, V.; Fedi, S.; Armanini, F.; Truong, D.T.; Manara, S.; Zolfo, M.; et al. Mother-toInfant Microbial Transmission from Different Body Sites Shapes the Developing Infant Gut Microbiome. Cell Host Microbe 2018, 24, 133-145.e5. [CrossRef] [PubMed]

54. Grönlund, M.-M.; Grześkowiak, Ł.; Isolauri, E.; Salminen, S. Influence of Mother's Intestinal Microbiota on Gut Colonization in the Infant. Gut Microbes 2011, 2, 227-233. [CrossRef] [PubMed]

55. Hooven, T.A.; Polin, R.A. Healthcare-Associated Infections in the Hospitalized Neonate: A Review. Early Hum. Dev. 2014, 90, S4-S6. [CrossRef]

56. Ramasethu, J. Prevention and Treatment of Neonatal Nosocomial Infections. Matern. Health Neonatol. Perinatol. 2017, 3, 5. [CrossRef] [PubMed]

57. Zingg, W.; Hopkins, S.; Gayet-Ageron, A.; Holmes, A.; Sharland, M.; Suetens, C.; Almeida, M.; Asembergiene, J.; Borg, M.A.; Budimir, A.; et al. Health-Care-Associated Infections in Neonates, Children, and Adolescents: An Analysis of Paediatric Data from the European Centre for Disease Prevention and Control Point-Prevalence Survey. Lancet Infect. Dis. 2017, 17, 381-389. [CrossRef]

58. Ericson, J.E.; Popoola, V.O.; Smith, P.B.; Benjamin, D.K.; Fowler, V.G.; Benjamin, D.K.; Clark, R.H.; Milstone, A.M. Burden of Invasive Staphylococcus Aureus Infections in Hospitalized Infants. JAMA Pediatr. 2015, 169, 1105. [CrossRef]

59. Giuffrè, M.; Amodio, E.; Bonura, C.; Geraci, D.M.; Saporito, L.; Ortolano, R.; Corsello, G.; Mammina, C. Methicillin-Resistant Staphylococcus Aureus Nasal Colonization in a Level III Neonatal Intensive Care Unit: Incidence and Risk Factors. Am. J. Infect. Control 2015, 43, 476-481. [CrossRef]

60. Dong, Y.; Glaser, K.; Speer, C.P. New Threats from an Old Foe: Methicillin-Resistant Staphylococcus Aureus Infections in Neonates. NEO 2018, 114, 127-134. [CrossRef]

61. Boyce, J.M.; Potter-Bynoe, G.; Chenevert, C.; King, T. Environmental Contamination Due to Methicillin-Resistant Staphylococcus Aureus: Possible Infection Control Implications. Infect. Control Hosp. Epidemiol. 1997, 18, 622-627. [CrossRef] [PubMed]

62. Wagenvoort, J.H.T.; Sluijsmans, W.; Penders, R.J.R. Better Environmental Survival of Outbreak vs. Sporadic MRSA Isolates. J. Hosp. Infect. 2000, 45, 231-234. [CrossRef]

63. Dong, Y.; Speer, C.P. The Role of Staphylococcus Epidermidis in Neonatal Sepsis: Guarding Angel or Pathogenic Devil? Int. J. Med. Microbiol. 2014, 304, 513-520. [CrossRef]

64. Fridkin, S.K.; Kaufman, D.; Edwards, J.R.; Shetty, S.; Horan, T. Changing Incidence of Candida Bloodstream Infections Among NICU Patients in the United States: 1995-2004. Pediatrics 2006, 117, 1680-1687. [CrossRef]

65. Leibovitz, E.; Livshiz-Riven, I.; Borer, A.; Taraboulos-Klein, T.; Zamir, O.; Shany, E.; Melamed, R.; Rimon, O.-F.; Bradenstein, R.; Chodick, G.; et al. A Prospective Study of the Patterns and Dynamics of Colonization with Candida Spp. in Very Low Birth Weight Neonates. Scand. J. Infect. Dis. 2013, 45, 842-848. [CrossRef]

66. Aliaga, S.; Clark, R.H.; Laughon, M.; Walsh, T.J.; Hope, W.W.; Benjamin, D.K.; Kaufman, D.; Arrieta, A.; Benjamin, D.K.; Smith, P.B. Changes in the Incidence of Candidiasis in Neonatal Intensive Care Units. Pediatrics 2014, 133, 236-242. [CrossRef] [PubMed]

67. Stoll, B.J.; Hansen, N.; Fanaroff, A.A.; Wright, L.L.; Carlo, W.A.; Ehrenkranz, R.A.; Lemons, J.A.; Donovan, E.F.; Stark, A.R.; Tyson, J.E.; et al. Late-Onset Sepsis in Very Low Birth Weight Neonates: The Experience of the NICHD Neonatal Research Network. Pediatrics 2002, 110, 285-291. [CrossRef] [PubMed] 
68. Senn, V.; Bassler, D.; Choudhury, R.; Scholkmann, F.; Righini-Grunder, F.; Vuille-dit-Bile, R.N.; Restin, T. Microbial Colonization from the Fetus to Early Childhood-A Comprehensive Review. Front. Cell. Infect. Microbiol. 2020, 10. [CrossRef] [PubMed]

69. Coscia, A.; Bardanzellu, F.; Caboni, E.; Fanos, V.; Peroni, D.G. When a Neonate is Born, So is a Microbiota. Life 2021, 11, 148. [CrossRef] [PubMed]

70. Sehgal, R.; Gaind, R.; Chellani, H.; Agarwal, P. Extended-Spectrum Beta Lactamase-Producing Gram-Negative Bacteria: Clinical Profile and Outcome in a Neonatal Intensive Care Unit. Ann. Trop. Paediatr. 2007, 27, 45-54. [CrossRef]

71. Folgori, L.; Bernaschi, P.; Piga, S.; Carletti, M.; Cunha, F.P.; Lara, P.H.; De, N.C.P.; Alves, B.G.; Sharland, M.; Araujo, A.d.S.; et al. Healthcare-Associated Infections in Pediatric and Neonatal Intensive Care Units: Impact of Underlying Risk Factors and Antimicrobial Resistance on 30-Day Case-Fatality in Italy and Brazil. Infect. Control Hosp. Epidemiol. 2016, 37, 1302-1309. [CrossRef]

72. Mehta, Y.; Gupta, A.; Todi, S.; Myatra, S.; Samaddar, D.P.; Patil, V.; Bhattacharya, P.K.; Ramasubban, S. Guidelines for Prevention of Hospital Acquired Infections. Indian J. Crit. Care Med. 2014, 18, 149-163. [CrossRef]

73. Shane, A.L.; Sánchez, P.J.; Stoll, B.J. Neonatal Sepsis. Lancet 2017, 390, 1770-1780. [CrossRef]

74. Clark, R.H.; Bloom, B.T.; Spitzer, A.R.; Gerstmann, D.R. Reported Medication Use in the Neonatal Intensive Care Unit: Data from a Large National Data Set. Pediatrics 2006, 117, 1979-1987. [CrossRef] [PubMed]

75. Dancer, S.J. The Role of Environmental Cleaning in the Control of Hospital-Acquired Infection. J. Hosp. Infect. 2009, 73, 378-385. [CrossRef]

76. Carling, P.C.; Parry, M.F.; Von, S.B. Identifying Opportunities to Enhance Environmental Cleaning in 23 Acute Care Hospitals. Infect. Control Hosp. Epidemiol. 2008, 29, 1-7. [CrossRef] [PubMed]

77. Goodman, E.R.; Platt, R.; Bass, R.; Onderdonk, A.B.; Yokoe, D.S.; Huang, S.S. Impact of an Environmental Cleaning Intervention on the Presence of Methicillin-Resistant Staphylococcus Aureus and Vancomycin-Resistant Enterococci on Surfaces in Intensive Care Unit Rooms. Infect. Control Hosp. Epidemiol. 2008, 29, 593-599. [CrossRef]

78. Bock, L.J.; Wand, M.E.; Sutton, J.M. Varying Activity of Chlorhexidine-Based Disinfectants against Klebsiella Pneumoniae Clinical Isolates and Adapted Strains. J. Hosp. Infect. 2016, 93, 42-48. [CrossRef] [PubMed]

79. Wand, M.E.; Bock, L.J.; Bonney, L.C.; Sutton, J.M. Mechanisms of Increased Resistance to Chlorhexidine and Cross-Resistance to Colistin Following Exposure of Klebsiella Pneumoniae Clinical Isolates to Chlorhexidine. Antimicrob. Agents Chemother. 2016, 61. [CrossRef] [PubMed]

80. Fahimipour, A.K.; Ben Mamaar, S.; McFarland, A.G.; Blaustein, R.A.; Chen, J.; Glawe, A.J.; Kline, J.; Green, J.L.; Halden, R.U.; Van Den Wymelenberg, K.; et al. Antimicrobial Chemicals Associate with Microbial Function and Antibiotic Resistance Indoors. mSystems 2018, 3. [CrossRef]

81. Caselli, E.; D’Accolti, M.; Vandini, A.; Lanzoni, L.; Camerada, M.T.; Coccagna, M.; Branchini, A.; Antonioli, P.; Balboni, P.G.; Luca, D.D.; et al. Impact of a Probiotic-Based Cleaning Intervention on the Microbiota Ecosystem of the Hospital Surfaces: Focus on the Resistome Remodulation. PLoS ONE 2016, 11, e0148857. [CrossRef]

82. Caselli, E.; Brusaferro, S.; Coccagna, M.; Arnoldo, L.; Berloco, F.; Antonioli, P.; Tarricone, R.; Pelissero, G.; Nola, S.; La Fauci, V.; et al. Reducing Healthcare-Associated Infections Incidence by a Probiotic-Based Sanitation System: A Multicentre, Prospective, Intervention Study. PLOS ONE 2018, 13. [CrossRef]

83. Sundquist, A.; Bigdeli, S.; Jalili, R.; Druzin, M.L.; Waller, S.; Pullen, K.M.; El-Sayed, Y.Y.; Taslimi, M.M.; Batzoglou, S.; Ronaghi, M. Bacterial Flora-Typing with Targeted, Chip-Based Pyrosequencing. BMC Microbiol. 2007, 7, 108. [CrossRef] [PubMed]

84. Bolyen, E.; Rideout, J.R.; Dillon, M.R.; Bokulich, N.A.; Abnet, C.C.; Al-Ghalith, G.A.; Alexander, H.; Alm, E.J.; Arumugam, M.; Asnicar, F.; et al. Reproducible, Interactive, Scalable and Extensible Microbiome Data Science Using QIIME 2. Nat. Biotechnol. 2019, 37, 852-857. [CrossRef] [PubMed]

85. Quast, C.; Pruesse, E.; Yilmaz, P.; Gerken, J.; Schweer, T.; Yarza, P.; Peplies, J.; Glöckner, F.O. The SILVA Ribosomal RNA Gene Database Project: Improved Data Processing and Web-Based Tools. Nucleic Acids Res. 2013, 41, D590-D596. [CrossRef] [PubMed]

86. D'Accolti, M.; Soffritti, I.; Lanzoni, L.; Bisi, M.; Volta, A.; Mazzacane, S.; Caselli, E. Effective Elimination of Staphylococcal Contamination from Hospital Surfaces by a Bacteriophage-Probiotic Sanitation Strategy: A Monocentric Study. Microb. Biotechnol. 2019, 12, 742-751. [CrossRef] [PubMed]

87. Vandini, A.; Temmerman, R.; Frabetti, A.; Caselli, E.; Antonioli, P.; Balboni, P.G.; Platano, D.; Branchini, A.; Mazzacane, S. Hard Surface Biocontrol in Hospitals Using Microbial-Based Cleaning Products. PLoS ONE 2014, 9. [CrossRef]

88. Lozupone, C.; Hamady, M.; Knight, R. UniFrac-An Online Tool for Comparing Microbial Community Diversity in a Phylogenetic Context. BMC Bioinform. 2006, 7, 371. [CrossRef] 